\title{
Pyogenic Granuloma- a Case Report and Review
}

\author{
Dr. Bobby Kurian*, Dr. Sasirekha, Dr. Ebenezer \\ Department of Periodontics, Adhiparasakthi Dental College, Melmaruvathur, India \\ Corresponding author: bobbds2000@gmail.com
}

Received April 22, 2014; Revised June 03, 2014; Accepted June 03, 2014

\begin{abstract}
Exophytic gingival lesions represent some of the more frequently encountered lesions in the oral cavity. Some of these lesions are reactive in nature. Pyogenic granuloma is a relatively common benign mucocutaneous lesion occurring intra orally or extra orally. The exact etiopathogenesis remains unknown, although contributory factors include trauma, inflammation and infectious agents. Intraoral lesions are sometimes associated with pregnancy. Typically, pyogenic granuloma presents as an exuberant, red painless mass that easily bleeds, ulcerates and grows rapidly and is frequently seen on the gingiva. Treatment is surgical excision to exclude angiomatous proliferation. The condition is frequently associated with recurrence, and has more predilections towards females. Here by, presenting a case of pyogenic granuloma in a 40 years old male patient.
\end{abstract}

Keywords: exophytic, benign mucocutaneous lesion, inflammatory hyperplasia

Cite This Article: Dr. Bobby Kurian, Dr. Sasirekha, and Dr. Ebenezer, "Pyogenic Granuloma- a Case Report and Review." International Journal of Dental Sciences and Research, vol. 2, no. 3 (2014): 66-68. doi: 10.12691/ijdsr-2-3-5.

\section{Introduction}

Pyogenic granuloma, also called as granuloma pyogenicum is a reactive inflammatory hyperplasia which appears in response to various stimuli such as low grade local irritation and traumatic injury [3]. The first case was reported in 1844 by Hullihen and the term pyogenic granuloma was coined only in 1904 by Hartzell. The term is a misnomer as it is not related to any infection, does not contain pus and is not a true granuloma. It develops in up to $5 \%$ of the pregnancies and hence terms like pregnancy tumor and granuloma gravidarum are commonly used [4]. The increased incidence of these lesions during pregnancy may be related to the increasing levels of estrogen and progesterone $[5,6]$. In majority of cases, minor trauma or irritation are cited in the etippathogenesis of pyogenic granuloma [7]. Infection may play a role with suggestions of agents such as streptococci and staphylococci [8]. Recently angiopoietin and ephrin B2 agents in other vascular tumors such as Bartonella hanselae, B.Quintana and human herpes virus 8 have been postulated to play a part in recurrent form [10]. Viral oncogenes, hormonal Influences, microscopic arterivenous malformation along with inclusion bodies and gene depression in fibroblast have all been implicated [11,12].

Clinically these lesions usually present as Single nodule or Sessile Papule with Smooth or lobulated Surface and maybe Seen in any size from a few millimeters to Several Centimeters. As lesion mature, the vascularity decreases and the clinical appearance are more collagenous and pink. The peak prevalence is in teenagers and young adults with a female predilection. It preferentially affects the gingiva, but may also occur on the lips, tongue, oral mucosa and palate $[13,14,15]$. Surgical excision is the treatment of choice, followed by curettage of the underlying lesion $[16,17]$.

\section{Case report}

A 39 year old male patient reported to the outpatient department of oral medicine and radiology, faculty of dentistry, adhi parasakthi dental college, Melmaruvathur, with a complain of localized gingival over growth for 3 months. The mass was not painful but often bled while eating, rinsing and sometime spontaneously. Extra oral examination was non-significant. Intra oral examination revealed an irregular, sessile exuberant growth in respect to buccal aspect and interdental gingiva of 44, 45, and 46, measuring about $4 \times 2.5 \mathrm{cms}$. This discrete lobular growth was covering almost two-third of crown of 44 and 45 . On palpation, the growth was soft in consistency, tender and bleeds profusely on probing. The patient was in poor oral hygiene. Grade I mobility of 44 and 45 was seen. Based on the clinical findings, the case was provisionally diagnosed as “pyogenic granuloma”. Intra oral periapical radiograph was taken and no bony involvement was seen. Routine hematologic tests were seen within normal range. After the informed consent of the patient, excisional biopsy was done and the lesion was sent for histopathologic evaluation. The patient was advised postoperative antibiotics, analgesic and maintainence of oral hygiene measures. The excised specimen showed hyperplastic stratified parakeratotic squamous epithelium with an underlying fibrovascular stroma. The stroma consisted of large number of budding and dilated capillaries, plump fibroblast, areas of extravasated blood and dense inflammatory cell infiltrates. The above histopathologic findings were suggestive of pyogenic granuloma. 


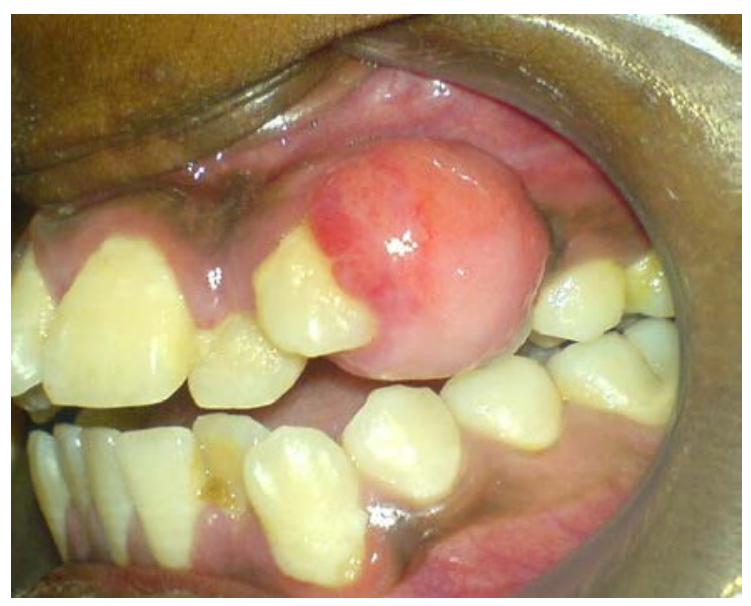

Figure 1. Pre - operative image showing pyogenic granuloma

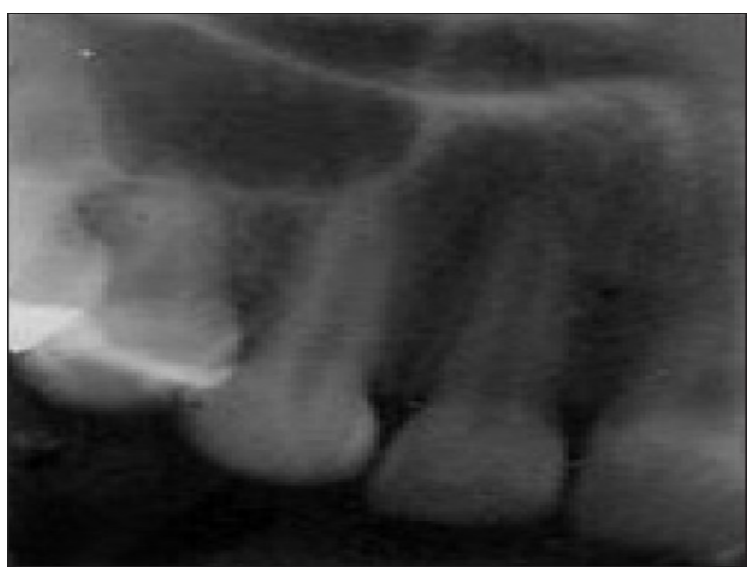

Figure 2. Radiographic image

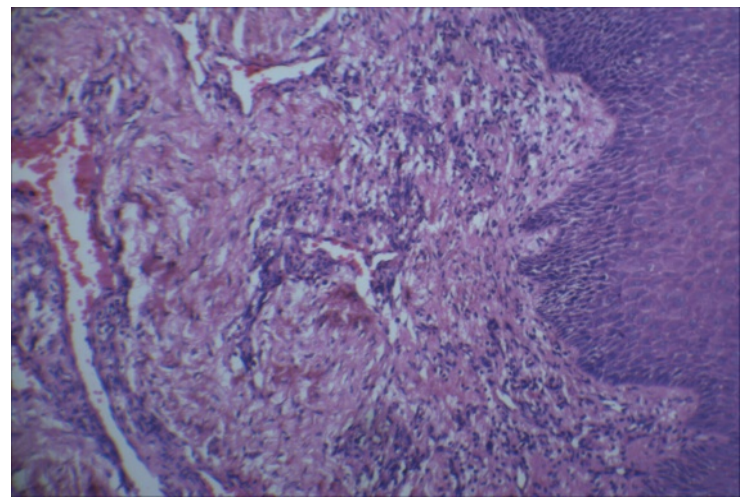

Figure 3. Histopathologic feature

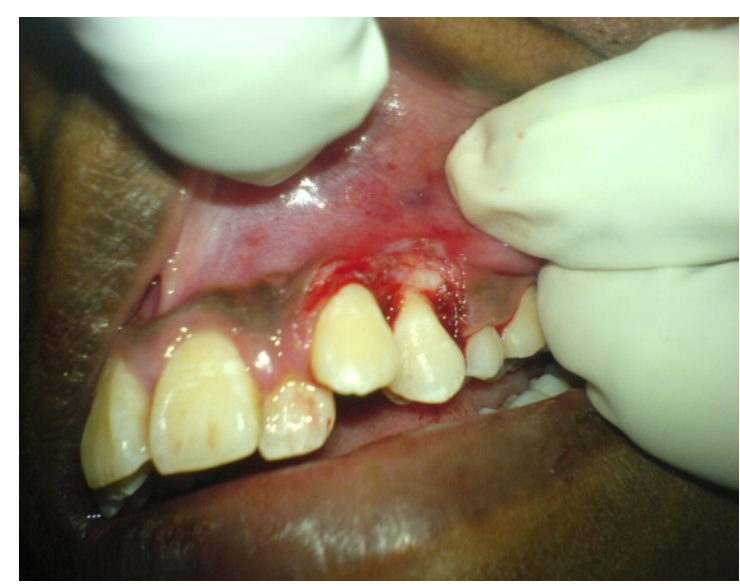

Figure 4. Immediate post- operative

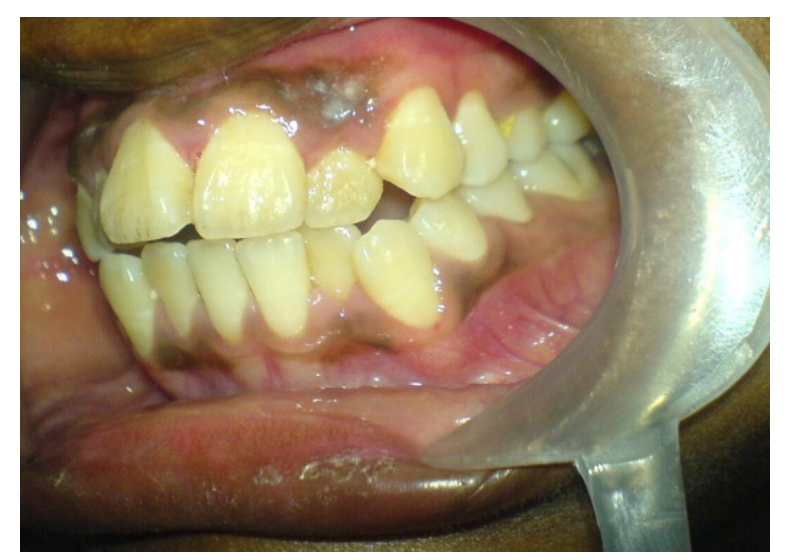

Figure 5. Post- operative after one month

\section{Discussion}

Pyogenic granuloma is a kind of inflammatory hyperplasia. The term inflammatory hyperplasia is used to describe a large range of nodular growths of the oral mucosa that histologically represents inflamed fibrous and granulation tissue $[18,19]$. There are two kinds of pyogenic granuloma namely lobular capillary hemangioma (LCH type) and non LCH type, which differs in their histological features. Poncet and Dor in 1897 first described pyogenic granuloma. Over the years various authors have suggested other names such as granuloma gravidarum, pregnancy tumor, crocker and hartzell's disease, vascular epulis, benign vascular tumor, hemangiomatosis granuloma, epulis teleangiectaticum granulomatosa, and lobular capillary hemangioma [20,21].

Approximately one third of the lesions occur after trauma, so the history of trauma before development of this lesion is not usual [1]. Poor oral hygiene may be a precipitating factor in many of these patients $[6,13,18]$. Some factors such as inducible nitric oxide synthase, vascular endothelial factor, fibroblast growth factor, or connective tissue growth factor are known to be involved in angiogenesis and rapid growth of pyogenic granuloma.

Clinically pyogenic granuloma is a smooth or lobulated exophytic lesion manifesting as small, red erythematous papule on a pedunculated or sessile base, varying in diameter from few millimeters to centimeters. The surface is ulcerated and friable which may be covered by a yellow, fibrinous membrane and its color ranges from pink to purple depending upon the age of the lesion [6,13]. The consistency of the tumor gets firmer both with aging of the lesion and elimination of its etiological factors. Its color ranges from pink to red to purple, depending on the age of the lesion. Young pyogenic granulomas are highly vascular in appearance because they are composed predominantly of hyperplastic granulation tissue in which capillaries are prominent [6]. Thus minor trauma to the lesion may cause considerable bleeding, due to its pronounced vascularity. Whereas older lesions tend to become more collagenized and pink $[6,13]$.

Oral pyogenic granuloma is the most common gingival tumor accounting for $75 \%$ of all cases. The lips, tongue, and buccal mucosa are the next most common site $[6,13,18]$. In the oral cavity pyogenic granulomas show a striking predilection for the gingiva, with interdental papillae being the most sites in $70 \%$ of the cases. They are 
more common in the maxillary anterior area than any other areas in the mouth. Gingival irritation and inflammation that result from poor oral hygiene, dental plaque and calculus or over hanging margins restorations may be precipitating factors in many cases $[6,19]$. Pyogenic granulomas of head and neck are uncommonly seen extra gingivally in areas of frequent trauma such as the lower lip, tongue and palate $[6,17]$.

Although pyogenic granuloma can be diagnosed clinically with considerable accuracy, radiographic and histopathological investigations aid in confirming the diagnosis and treatment. Radiographs are advised to rule out bony destructions suggestive of malignancy or to identify a foreign body. Differential diagnosis of pyogenic granuloma includes peripheral giant cell granuloma, peripheral ossifying fibroma, metastic cancer, hemangioma, basillary angiomatosis, angiosarcoma and non Hodgkins lymphoma [22].

Management of pyogenic granuloma depends on the severity of sympoms. If the lesion is small, painless and free of bleeding, clinical observation and follow up are advised [23]. Other treatment modalities include laser surgery, electrodessication [24,25]. Injection of absolute ethanol, sodium tetradecyl sulfate (sclerotherapy) and corticosteroids have also been tried with successful results in cases with recurrent lesions [26,27]. Recurrence occurs in upto $16 \%$ of the lesions, which might be due to incomplete excision, failure to remove etiologic factors, or due to reinjury to the area, making follow up necessary $[28,29]$.

\section{Conclusion}

Pyogenic granulomas are commonly encountered soft tissue enlargements. Careful diagnosis is essential to differentiate this lesion from vascular lesions. Meticulous oral hygiene should be instituted. Surgical excision of the growth, along with curettage should be done to prevent recurrences of this common lesion.

\section{References}

[1] Ababneh KT. Biopsied gingival lesions in northern Jordanians: A retrospective analysis over 10 years. Int J Periodontics restorative Dent. 2006 Aug; 26: 387-93.

[2] Bataineh A, Al-Dwairi ZN. A survey of localized lesions of oral tissues: a clinicopathological study. J Contemp Dent Pract. 2005 Aug 15; 6: 30-39.

[3] Bhaskar SN, Jacoway JR. Pyogenic granuloma clinical features, incidence, histology and result of treatment: report of 242 cases. J Oral Surg. 1966; 24: 391-99.

[4] Mubeen K, Vijayalakshmi KR, Abhishek RP. Oral pyogenic granuloma with mandible involvement: an unusual presentation. J Dent Oral Hyg. 2011; 3: 6-9.
[5] Ramirez K, Bruce G, Carpenter W. Pyogenic granuloma: a case report in a 9 year old girl. Gen Dent. 2002; 50: 280-281.

[6] Nevile BW, Damm DD, Allen CM, Bouquot JE. Oral and maxillofacial pathology. $2^{\text {nd }}$ ed. W.B. Saunders; 2004. pp. 437-495.

[7] Mac loed RL, Soames J. Ephillides: A Clinicopathologic study of 200 consecutive lesions. British Dental Journal. 1987: 163; 51-53.

[8] Levy I, Rolain JM, Lepidi H. Is pyogenic granuloma associated with bartonella infection? J Am Acad Dermatol 2005; 55: 10651066.

[9] Yuan K, Jin YT, Lin MT. Expression of tie-2, angiopoitin-1-2, ephrin B2, ephrin B4, in pyogenic granuloma of human gingival implicating inflammatory angiogenesis. J Periodontal Research. 2000: 35; 165-167.

[10] Janier M. Infection and angiomatous cutaneous lesions. J Mal Vasc. 1999; 24 (2): 135-138.

[11] Davies MG, Borton SP, Atai F. The abnormal dermis in pyogenic granuloma. J Am Acad Dermatol 2000; 35: 342-344.

[12] Vilamnn A, Vilamnn P, Vilamnn H.Pyogenic granuloma: evaluation of oral conditions. Br J Oral Maxillofac Surg. 1986; 24: 376-382.

[13] Ragezi JA, Sciubba, James J, Jordan Richors CK. Oral Pathology, Clinical pathologic correlation. Fourth. Sanders Company; 2003. pp. 115-176.

[14] Akyol MU, Yalciner EG, Dolan AI. Pogenic granuloma of the tongue. Int J Pediatr Otorhinolaryngol. 2001; 58: 239-241.

[15] Glorgi VD, Sestini S, Nardini P, Cali P.A 42yr old man with a rapidly growing lesion of the soft palate. CMAJ. 2005; 173: 367

[16] Peter A, Reichert, Hans Peter Philipsen. Color atlas of oral medicine pathology. Stuttgart. Theme. 2000; pg 163.

[17] Patil K, Mahima VG, Lahari K. Extragingival pyogenic granuloma. Indian J Dent Res 2006; 17: 199-202.

[18] Eversole Lr. Clinical Outline Of Oral pathology:Diagnosis And Treatment, 3 Ed, Bc Decker, Hamilton, 2002; 113-114.

[19] Greenberg MS, Glick M. Burket's oral medicine:diagnosis and treatment. $10^{\text {th }}$ ed, BC Decker, Hamilton, 2003: 141-2.

[20] Graham RM. Pyogenic granuloma: an unusual presentation. Dent update. 1996; 26 (1): 240-241.

[21] Bjork K, Hoede N, Korting GW, Burgdorf WHC, Young SK. Disease of the oral mucosa and the lips. Philadelphia: WB Sauders; 1996. Pp. 229-230.

[22] Calonje E, Wilson-Jones E. Vascular tumors: tumor like conditions of blood vessels and lymphatics. In: Elder D, Elenitsas $\mathrm{R}$, Jaworsky C, Johnson Bj, eds. Lever's histopathology of skin. $8^{\text {th }}$ ed. Philadelphia: Lippincott-Raven; 1997. P. 895.

[23] Sils ES, Zegarelli DJ, Hoschander MM, Strider WE. Clinical diagnosis and management of hormonally responsive oral pregnancy tumor. J Reprod Med. 1996; 41: 467-470.

[24] White JM, Chaudhry SI, Kudler JJ, Sekandari N, Schoelch ML, Silverman S Jr. Nd: Yag and cO2 laser therapy of oral mucosal lesions. J Clin Laser Med Surg. 1998; 16: 299-304.

[25] Ishida CE, Ramos-E-Silva M. Cryosurgery in oral lesions. Int J Dermatol. 1998; 37: 283-285.

[26] Ichimaya M, Yoshikawa Y, Hamamoto Y, Muto M. Successful treatment of pyogenic granuloma with absolute alcohol. J Dermatol. 2004; 31: 342-344.

[27] Moon SE, Hwang EJ, Cho KH. Treatment of pyogenic granuloma by sodium tetradecyl sulphate sclerotherapy. Arch Dermatol. 2005; 141: 644-646.

[28] Taira JW,Hill TL, Everett MA. Lobular capillary hemangioma with satellitosis. J Am Acad Dermatol. 1992; 27: 297-300.

[29] Selvamuthukumar SC,Nalini Ashwath, Anand V. Unusual presentation of pyogenic granuloma of buccal mucosa. JIAOMR. 2010; 22 (4): S 45-47. 